\title{
Factors Affecting the Consumption of Contemporary Art Jewelry in Beijing China
}

\author{
Hongyu Chen, Manoch Prompanyo \\ School of Management, Shinawatra University, Bangkok, Thailand \\ Email: chenxiaoyu614@foxmail.com, fuangfa.a@siu.ac.th
}

How to cite this paper: Chen, H. Y., \& Prompanyo, M. (2021). Factors Affecting the Consumption of Contemporary Art Jewelry in Beijing China. American Journal of Industrial and Business Management, 11, 664674.

https://doi.org/10.4236/ajibm.2021.116043

Received: May 6, 2021

Accepted: June 20, 2021

Published: June 23, 2021

Copyright (c) 2021 by author(s) and Scientific Research Publishing Inc. This work is licensed under the Creative Commons Attribution International License (CC BY 4.0).

http://creativecommons.org/licenses/by/4.0/

\begin{abstract}
In the 40 years of China's reform and opening up, the jewelry market has changed from a traditional market to a fashion market that reflects individual aesthetics. People's demand for jewelry is not only a decorative effect, but also a jewel to reflect their aesthetic relationship. The future of contemporary art jewelry will gradually occupy its share in the jewelry market. From the international jewelry market to the Chinese jewelry market, the economic volume is changing, the consumption of traditional jewelry is decreasing, and contemporary art jewelry is gradually becoming the object of consumption. The purpose of this study is to explore the factors that influence the consumption of contemporary art jewelry, which is equivalent to doing a good job in premarket research for the development of marketing strategy research. This study studies the factors influencing the consumption of contemporary art jewelry through quantitative research methods. The main variables are products, consumers, and advertising. In this study, 423 questionnaires were obtained from the citizens of Beijing, China, and the results were analyzed by SPSS one-way analysis of variance, weight analysis, and fundamental analysis. The research results show that consumers, products, and advertising have a relatively important impact on contemporary art jewelry consumption.
\end{abstract}

\section{Keywords}

Contemporary Art Jewelry, Consumption, Beijing, China

\section{Introduction}

From the perspective of the development of the international contemporary art market, art jewelry started in the early 1960s, but there is no corresponding market to echo this new art movement. It was not until the end of 1980 that Peter Chung began to appear in the Netherlands and Germany. In 1988, Peter held his first solo exhibition at RA gallery in the Netherlands. In the European market 
at that time, galleries, galleries and private collectors were three important parts of the art jewelry market, which promoted and supported the emerging jewelry artists at that time (Cao Ruiqi, 2003). In 2009, katharina was selected as the graduate work of Schmuck 2010, the most influential contemporary jewelry exhibition in Europe in 2010. In just two years, katharina has sold more than 15 works for prices ranging from 150 euros to 2500 euros. In the 1980s, European art colleges and universities successively developed contemporary art jewelry majors, and more and more designers were engaged in contemporary art jewelry (Di Yuzhao, 2008).

From the perspective of the development of China's contemporary art jewelry market, it was only at the beginning of the 21 st century that contemporary art jewelry design majors were started in major art colleges and universities in China (Cheng Qiaoming, 2004). At present, there are 64 art colleges and universities offering jewelry design majors in China, 13 of which have set up contemporary art jewelry. In the 20 years' development of contemporary art jewelry in China, the process of our contemporary art jewelry to the market is relatively backward. At present, the promotion of Chinese concept jewelry in the market in recent years is still in the initial stage, and the independent studio is just budding (Hao Qi, 2008). The company has become a powerful promoter of concept jewelry marketization. Art jewelry has been developing for decades in the world, but in China, art jewelry has just started. With the increasing demand for personalized jewelry, contemporary art jewelry will also become more and more popular. Through the research and introduction of this paper, it will provide a broader perspective for jewelry design practitioners in China, strengthen the emphasis on individuality and creativity, and further strengthen the proportion of artistic added value in commercial jewelry. It can be seen that the research content of this paper has both theoretical and practical significance (Gan Dachuan, 2005).

In short, no matter in the international market or the domestic market, people have higher and higher requirements on personality, ideas and aesthetics. However, contemporary art jewelry is meeting the needs of the public for artistic aesthetics (Hu Jun, 2012). The function of traditional jewelry may be to decorate, wear and preserve the value of the family, but the contemporary art jewelry more reflects the personal taste and aesthetics. Theoretically speaking, contemporary art jewelry should be a fresh power and market power like concept clothing, concept car and concept mobile phone (Jiang Changcheng, 2008). Because whether it's concept clothing, concept car or concept phone, some incredible research and creation in the past have now entered into People's Daily life. In China, research on conceptual jewelry has been concentrated in ivory towers such as university campuses (Ma Jian, 2008). There are few innovations and researches related to the market. In fact, contemporary art jewelry has a unique artistic concept. However, there is extremely strong demand for concept jewelry in different styles. Because of the factors of consumers, contemporary art itself and advertising, it will affect everyone's purchase of contemporary art jewelry (Shi Yuyu, 2008). Through the research of this paper, we can find out what are the impor- 
tant factors for the purchase of contemporary art jewelry and the consumption of contemporary art jewelry.

Jewelry consumption market has been studied by some researchers in previous works. The jewelry industry's global annual sales volume is 148 billion euros in 2020, which is expected to grow at a healthy rate of $5 \%$ to $6 \%$ annually and reach 250 billion euros by 2020, which proves that the economic volume of the jewelry market is very large (San Tiancun \& You Fang, 2011). Researchers have studied contemporary art jewelry. Fang Wei (2008) proves that contemporary art jewelry is developing at a high speed, and art jewelry modeling is becoming more and more popular among people. The author mainly studies the development of contemporary art jewelry, but does not study what factors really affect the consumption of contemporary art jewelry based on the behavior of market consumers. Concept jewelry is a young art category (Guo Xin, 2006). In general, the cutting-edge research on conceptual jewelry is very innovative, so it is both innovative and innovative in the field of art and jewelry, unique and leading research. Whether at home or abroad, it is an art category with great exploration space (Ma Jian, 2008). However, what we need to do is not only to explore the artistic nature of conceptual jewelry, but also to further study its relationship with the market. Jewelry professional institute of contemporary art in the global development at present, there are 97 admissions to reach more than 2000 people each year, college of art in Europe 40 years or so, this major has opened in China for this major also have 20 years or so, as people pursuit of aesthetic is higher and higher, the number of the industry will be more and more, but rarely jewelry market consumption lack of contemporary art. Current global engaged in contemporary art jewelry designer has about 3000 people, is engaged in this industry in China, about 1000 people around there are about 50,000 pieces of works of stock on the market, but through market research, found that the best three global contemporary art jewelry making network sales platform Kt2, AJF, Benchpeg, total sales of about 8000 a year, so the contemporary art jewelry consumption is much lower than production. As a consumption-oriented industry, only by gaining recognition in the market can contemporary art jewelry designers continuously create works (Knee Philippine, 2006). The mass consumption of jewelry is increasing, while the consumption of contemporary art jewelry is seriously low. The influence of contemporary art jewelry consumption may be due to the insufficient popularity of contemporary art jewelry, or the lack of sales channels of contemporary art jewelry. This paper studies the factors that affect the consumer behavior of contemporary art jewelry, including personal factors and social factors, social factors including cultural factors, psychological factors, political factors and so on. The research reveals the change rule of consumption behavior. In this paper, two questions are discussed.

1) What are the factors that influence consumers' sales of contemporary jewelry?

2) By studying the factors we have learned, how should we develop marketing 
strategies to increase the consumption of contemporary art jewelry?

\section{Materials and Methods}

This project focused on a quantitative approach since the literature review revealed that a considerable amount of work had been done in terms of understanding the issues of customer's future behavioral intention in other contexts. Further, validated quantitative instruments have been used to explore these areas and, with suitable precautions, it was deemed appropriate to extend them to the Factors influencing the consumption of Chinese contemporary art jewelry in Beijing China. Based on the literature review and the research questions, the following hypotheses were created:

H1 Demographic characteristics of customers have a significant impact on the consumption of contemporary art jewelry.

H2 Marketing factors have a significant impact on the consumption of contemporary art jewelry.

These hypotheses were converted to null format for formal testing. They may be represented by the conceptual framework (see Figure 1, below).

The individual variables within these subsets have been tested and validated in a variety of peer-reviewed academic papers. Specifically, variants of the current posited model have been employed in a range of different influencing factors.

\section{Methods}

This study is a quantitative research design that uses a questionnaire to collect customer groups in Beijing. Through a large amount of literature, we found that the main factors affecting the sales of contemporary art jewelry are: the consumer itself, the product itself, and advertising. I will design a questionnaire for these three variables. Because of the limitations of research time and financial resources, this study used a convenient sampling of non-random sampling to collect data from visitors.

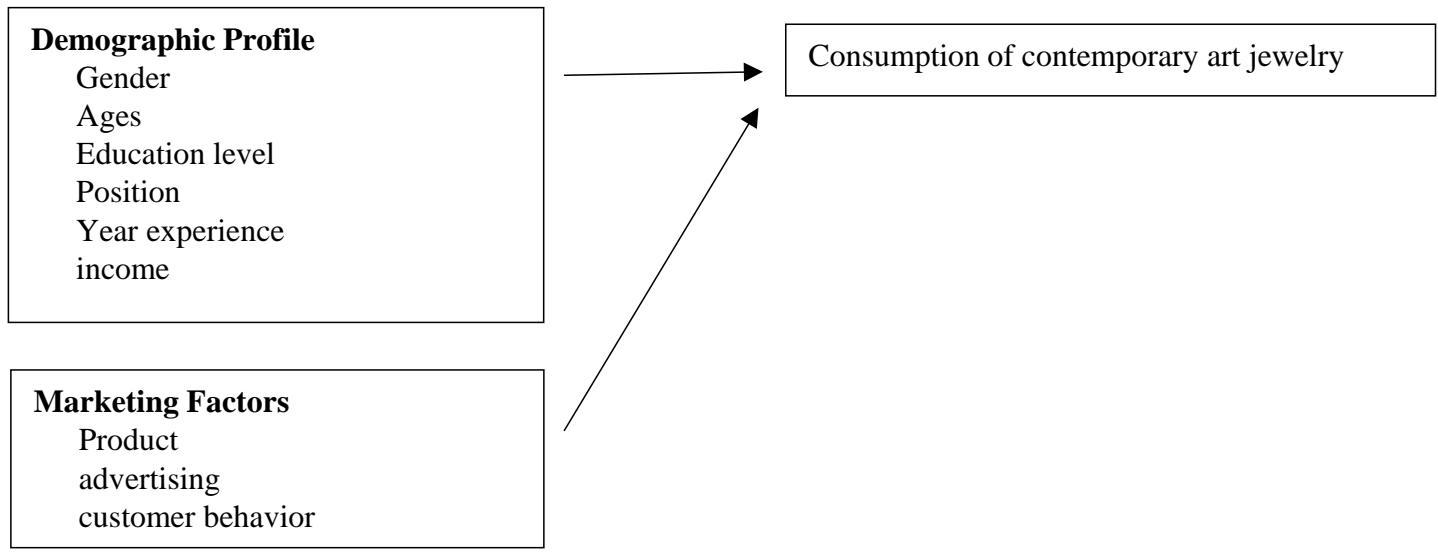

Figure 1. Conceptual framework; Source: Authors. 
In terms of research, quantitative techniques are used because quantitative research has been widely used in the human resources management research academic community. The sample size of this study is relatively large. Quantitative research begins with a tested theory, processing numbers and statistics, and theories or models are identified, modified, or discarded. Quantitative methods involve the process of collecting, analyzing, interpreting, and writing research results. There are specific methods related to identifying samples and populations in surveys and experimental studies, specifying survey strategies, collecting and analyzing data, presenting results, interpreting, and writing research studies in a manner consistent with surveys or experiments. Qualitative research begins with data, primarily dealing with non-digital data, and theories or models are derived from data and can be compared to other theories or models.

All data, including research backgrounds, topic-related concepts, theory and past research, from commercial portals, authoritative third-party survey agencies, books and academic journals. The demographics of the respondents were collected through questionnaires, as well as the respondents' understanding of contemporary art jewelry products and the awareness of advertising. The survey aims to examine the main factors affecting the consumption of contemporary art jewelry, with direct and indirect effects.

First of all, through the review of relevant literature and past research, the index system of questionnaires affecting contemporary art jewelry was initially formed. Since the respondent questionnaire was first written in Chinese, the five human resource management professors submitted to China conducted an IOC (Project-Objective-Congruence) test and then modified the questions raised based on the test results obtained by the IOC from the experts.

Secondly, the author translated the original Chinese standard into an English version, and then the author compare the original Chinese version with the translated English version to check the consistency of the meaning of the items in the scale, and modified the unclear with Thailand. Human resource management professors discuss inconsistent expressions.

Third, 30 pre-test questionnaires will be released to test the intelligibility, reliability and effectiveness of the initial questionnaire. Then, according to the results of the pilot, modify the language expression of some projects to understand the respondents.

Fourth, a final questionnaire will be issued to the respondents.

This study is a quantitative study design using a questionnaire. The design of the questionnaire must follow the following principles: 1) Purpose principle: The main purpose of the questionnaire is to provide information needed for management decision-making to meet the information needs of decision makers. The questionnaire designer must have a thorough understanding of the subject of the survey project and be able to draw up the questions that can get the most information from the respondent, so as not to omit a question and make the required information incomplete. 2) Logic principle: For a successfully designed questionnaire, the questions should be arranged in a certain logical order, which 
conforms to the thinking process of the respondent. 3) Popularity principle: If the interviewee is not interested in the survey topic, they will generally not participate in the survey. One of the most important tasks of questionnaire design is to make the question suitable for the potential respondent, and to enable the respondent to fully understand the question sentence and be willing to answer and answer correctly. 4) The principle of ease of processing: ease of processing means to make the respondent's answers easy for inspection, data processing and analysis.

There are three major parts in this research questionnaire. The first part is mainly to explain the questionnaire. Because many people don't know contemporary art jewelry, this study will briefly introduce what is contemporary art jewelry, the difference between contemporary art jewelry and other jewelry before answering the question. Add some pictures of typical contemporary art jewelry. The second part is personal background information, mainly the basic information of age, occupation, education, income and so on. The third part is the three variables that influence the sales of contemporary art jewelry, consumers, products, advertising, designing questionnaires around three variables, one variable with three variable factors, three factors for each factor, and a total of 27 questions. This questionnaire uses the Likert Five Scale. The 1 - 5 indicates that it strongly disagrees and agrees very much. The respondents replied according to the applicability of the questions.

\section{Sample}

The sample size is calculated according to Beijing, which was expressed by the following formula:

$$
n=\frac{N}{1+N *(e)^{2}}
$$

$n$-the sample size;

$N$-the population size;

$e$ - the acceptable sampling error;

${ }^{*} 95 \%$ confidence level and $p=0.5$ are assumed.

In order to ensure the scientificity, reliability and accuracy of the research of the thesis, this paper adopts a random selection method to select samples to ensure the objectivity and accuracy of the research conclusions. Thus, the sample size is 423 . However, for easy to collect and process the data, the author collects the data from 423 samples.

The author will apply purposive sampling in order to collect the data from the sample.

\section{Questionnaire Pretest}

The pre-test of this research questionnaire was issued on June 20,2019. A total of 30 questionnaires were distributed through the Internet, 30 were recovered, and 30 valid questionnaires were collected. Reliability analysis is used to measure 
the consistency of the data. If the measurement is below a certain level, it means that the measurement may be inconsistent or not reflect the real situation. The reliability analysis is usually tested by Cronbach's Alpha. If the Cronbach's Alpha coefficient reaches 0.7 or higher, the reliability is high. This study questionnaire was pretested for reliability analysis by spss software in Table 1.

The reliability coefficient, the value of the Cronbach alpha coefficient, is between 0 and 1 . If the a coefficient does not exceed 0.6 , it is generally considered that the internal consistency is insufficient; when it reaches $0.7-0.8$, the scale has considerable reliability, and when it reaches $0.8-0.9$, the reliability of the scale is very good. The reliability of this study is $0.727,0.799$, and 0.846 , indicating that the research scale has high reliability and good stability and consistency.

Kmo metric: 0.9 or more means very suitable; 0.8 means suitable; 0.7 means general; 0.6 means less suitable; 0.5 or less means extremely unsuitable. The validity of this analysis is $0.905,0.891$ and 0.844 , respectively, indicating that the validity is very good in Table 2.

\section{Respondent Demographics}

A total of 423 respondents in this study, the research found that majority of the respondents were females who are 232 persons accounting for $54.8 \%$, there are 191 persons accounting for $45.2 \%$. This proves that women prefer jewelry more than men. Respondents' ages were classified 5 groups which were Under 18, 19 30, 31 - 40, 41 - 50, and above 50. Findings from the survey results revealed that majority of the respondents were the age group of 19 - 30 years old (41.7\%), followed by the age groups of 31 - 40 years old (31.4\%), 41 - 50 years old (17.5\%), and 50 years old and over (5.2\%) respectively. majority of respondents are Married with children (70.0\%), Married with children (9.7\%), Single (16.1\%), and a very small part of respondents are others $(4.3 \%)$. revealed the majority of respondents were bachelor degree holders $(67.1 \%)$, followed by the respondents whose education level were lower than bachelor degree (12.5\%) and Higher than Master Degree $(20.3 \%)$. revealed the majority of respondents were Financial (14.7\%),

Table 1. Reliability statistics.

\begin{tabular}{ccc}
\hline & Clone Bach Alpha & item count \\
\hline Consumer's own factors & 0.946 & 9 \\
Product factor & 0.949 & 9 \\
Advertising & 0.947 & 9 \\
\hline
\end{tabular}

Table 2. Validity analysis.

\begin{tabular}{ccc}
\hline & Clone Bach Alpha & item count \\
\hline Consumer's own factors & 0.946 & 9 \\
Product factor & 0.949 & 9 \\
Advertising & 0.947 & 9 \\
\hline
\end{tabular}


Technology industry (7.6\%), culture and art (6.4\%), student (6.9\%) Education and training (8.5\%), service industry (9.9\%), Civil servant (10.2\%), Enterprises and institutions (9.7\%), Manufacturing Industry (10.4\%), Internet industry (8.5\%), Self-employment (1.9\%), other industry (5.4\%), we will find the most respondents in the financial industry. The majority of respondents were Lower than $5000 \mathrm{RMB}$ (13.7\%), 5000 - 10,000 RMB (35\%), 10,000 - 20,000 RMB (26.7\%), 20,000 - 50,000 RMB (20.6\%), above 50,000 RMB (4\%). We will find the most respondents with incomes between 5000 and 10,000 RMB. The majority of respondents were Lower than $500 \mathrm{RMB}$ (19.4\%), 501 - $2000 \mathrm{RMB}$ (23.4\%), 2001 - 5000 RMB (17.7\%), 5001 - 8000 RMB (15.4\%), 8001 - 16,000 RMB (17\%), Above 16,001 RMB (7.1\%). We will find the most respondents with incomes between 5001 and $2000 \mathrm{RMB}$.

\section{Anova}

This research found from the age table: consumers $(\mathrm{Sig}=0.025)$, products $(\mathrm{Sig}=$ 0.075), advertising ( $\mathrm{Sig}=0.019)$. That age has significant Sig for consumers' own factors, product factors, and advertisements. The Sig is greater than 0.05 , indicating that consumers' own factors, product factors, and advertising are not significant among people without gender difference.

From the education of the table: consumers $(\mathrm{Sig}=0.167)$, products ( $\mathrm{Sig}=$ 0.139 ), advertising ( $\mathrm{Sig}=0.088$ ). The significant $p$ value of the degree of education on the consumer's own factors, product factors, and advertising propaganda is greater than 0.05 , indicating that consumers' own factors, product factors, and advertising are not significantly different among people with different academic qualifications.

From the industry of the table: consumers ( $\mathrm{Sig}=0.132)$, products $(\mathrm{Sig}=0.312)$, advertising ( $\mathrm{Sig}=0.454)$, that the significant $\mathrm{p}$-values of the occupation-toconsumer's own factors, product factors, and advertising propensity are greater than 0.05 , indicating that there are no significant differences between consumers' own factors, product factors, and advertising in different occupations.

From the marital status of the table: consumers ( $\mathrm{Sig}=0.472$ ), products ( $\mathrm{Sig}=$ 0.486 ), advertising ( $\mathrm{Sig}=0.599)$, that the marital status has a significant $\mathrm{p}$-value of more than 0.05 for the consumer's own factors, product factors, and propaganda. This indicates that the consumer's own factors, product factors, and advertising are not among the people in different marital status. Significant differences.

From the monthly income of the table: consumers ( $\mathrm{Sig}=0.307$ ), products (Sig $=0.353)$, advertising $(\mathrm{Sig}=0.329)$, that the personal monthly income has significant $p$ value of more than 0.05 for the consumer's own factors, product factors, and advertising propensity. This indicates that the consumer's own factors, product factors, and advertising are in different individuals' monthly income. No significant difference

From the product price of the table: consumers $(\mathrm{Sig}=0.477)$, products $(\mathrm{Sig}=$ 
0.307), advertising ( $\mathrm{Sig}=0.235)$, that the product price has significant $\mathrm{p}$ value of more than 0.05 for the consumer's own factors, product factors, and advertising propensity. This indicates that the consumer's own factors, product factors, and advertising are advertised at different product prices. There were no significant differences between the two.

\section{Hypothesis Tests}

Through the weight analysis, this study compares the influence of consumers, products and advertising on the consumption of jewelry in contemporary art history.

1) Among the three factors, the product factor weight is the highest, 0.3351 , of which the purchase motivation weight is the highest, the weight is 0.1124 ; the second is the advertising factor, the weight is 0.3345 , in which the product image weight is the highest, the weight is 0.1124 ; the consumer's own factor weight It is ranked 0.3303, ranking third, with the highest motivational weight and weight of 0.1120 .

2) Among the 9 dimensions, the purchase motivation and product image weight are the highest, reaching 0.1124 ; the emotional and personality weights are the lowest, 0.1081 and 0.1099 respectively.

3) Among the 27 variables, "A3 contemporary art jewelry can be used for collection." "E3 I think the price of contemporary art jewelry is value for money." "F1 I think the image of contemporary art jewelry is very trendy.", The weights are $0.3382,0.381$, and 0.3382 , respectively, ranking the top three; "B3 can buy contemporary art jewelry to enjoy the body and mind.", "C3 buys contemporary art jewelry to meet the diversified pursuit of life.", "E1 I think the price of contemporary art jewelry is stable.", the weights are $0.0355,0.0359,0.0356$, ranking the last three.

H1 Assume that demographic characteristics have an impact on the consumption of contemporary art jewelry.

This study found that demographic statistics of different age groups have a significant impact on advertising in contemporary art jewelry consumption (sig $=0.019$ ), proving that everyone needs more knowledge of contemporary art jewelry.

$\mathrm{H} 2$ Assume that the consumer itself, the product itself, and advertising have an impact on the consumption of contemporary art jewelry.

This research found among the three factors, the product factor weight is the highest, 0.3351 , of which the purchase motivation weight is the highest, the weight is 0.1124 ; the second is the advertising factor, the weight is 0.3345 , in which the product image weight is the highest, the weight is 0.1124 ; the consumer's own factor weight It is ranked 0.3303 , ranking third, with the highest motivational weight and weight of 0.1120 .

\section{Discussion}

From the above data, we found an important factor. Because contemporary art 
jewelry is a very rare piece of art, everyone knows very little about it, so whether it is all ages, men and women, different professions, different incomes, everyone's understanding. The degree is similar, so there is no significant difference. But for the advertising of contemporary art jewelry consumption, this independent variable is sig $=0.019$ for all ages, which shows that Dangdang art jewelry needs to be more popularized and spread. Not everyone doesn't like contemporary art jewelry, but everyone doesn't know the artistic features of contemporary art jewelry.

\section{Research Difficulty and Limitation}

1) In the course of the research, there is a lack of research on the current market consumption. Because the current market consumption is small, there is no purchasing system. Most customers who understand contemporary art jewelry are directly aware of contemporary art jewelry designers. Trading, so the specific sales volume, there is no way to obtain, increasing the difficulty of market research.

2) In the research of this research, the independent variables of the research are not comprehensive enough, and it is necessary to conduct research on the styles that customers like for contemporary jewelry to better guide the creative ideas of contemporary jewelry designers. Therefore, the product characteristics of the product itself are also independent variables, which will also affect the consumption of contemporary art jewelry.

\section{Conflicts of Interest}

The authors declare no conflicts of interest regarding the publication of this paper.

\section{References}

Cao, R. Q. (2003). The Gamification Tendency in Art Design. Art Observation, 93, 91-92. Cheng, Q. M. (2004). Art Industry Management. Kunming: Yunnan University Press, 10. Di, Y. Z. (2008). History of Jewelry. Harbin: Harbin Publishing House.

Fang, W. (2008). A Brief History of Modern Art Design in the World. Changsha: Central South University Press, 21-22.

Gan, D. C. (2005). Jewelry Design and Processing. Beijing: Chemical Industry Press.

Guo, X. (2006). Art Jewelry as a Form of Artistic Creation. Shanghai Arts and Crafts, 83, 63-65.

Hao, Q. (2008). Discussion on the Application of Wood Grain Metal Technology in Contemporary Chinese Jewelry Design. Beijing: China University of Geosciences..

Hu, J. (2012). On the Application of Metal Coloring in Modern Jewelry Design. Art and Design (Theory).

Jiang, C. C. (2008). Art Wealth. New and Old Competitions Jointly Promote the Rise of Chinese Contemporary Art. Changsha: Hunan Fine Arts Publishing House, 3.

Knee, P. (2006). The Fable of the Body, a Jewelry Design. Fuzhou: Fujian Fine Arts Publishing House. 
Ma, J. (2008). Economics of Art Market. China Times Economic Publishing House, 3.

San, T. C., \& You, F. (2011). Japanese Metal Craftsmanship Wood Grain Gold Research. Decoration.

Shi, Y. Y. (2008).Wearable Sculpture-Concept Jewelry Design Features. Art Theory. 